\title{
Effect of end chills, reinforcement content and carburization on the hardness of LM25-borosilicate glass particulate composite
}

\author{
A. Hiremath ${ }^{1}$, A. AmarMurthy ${ }^{1}$, S.V. Pranavathmaja ${ }^{1}$, A. Jajodia ${ }^{1}$ and \\ R. Sreenath ${ }^{1}$ \\ ${ }^{1}$ Department of Mechanical \& Manufacturing Engineering, Manipal Institute of \\ Technology, Manipal Academy of Higher Education, Karnataka, INDIA, 576104 \\ Phone: +919964255323; Fax: +918202571071 \\ *Email: anupama.hiremath@ manipal.edu
}

\begin{abstract}
Aluminium metal matrix composites (AMCs) are widely employed in aerospace and automobile applications. Thus, they are required to operate reliably under a severe corrosive, high temperature and carbonaceous environments, without undergoing any deterioration in their mechanical properties. The paper is the compilation of the experimental results and analysis carried out to investigate the effect of different end chills, reinforcement content and carburization on the LM 25 aluminium alloy reinforced with borosilicate glass powder. The composites are prepared via stir casting route by varying the weight percent (wt.\%) of the reinforcement starting from $3 \mathrm{wt} \%$ and going up till $12 \mathrm{wt} . \%$ with an increment of $3 \mathrm{wt} . \%$ in every step. To obtain quality castings, end chills are placed within the sand mould. The specimens drawn from the chill-end of the castings are pack carburized in a muffle furnace for a set duration of time. The hardness of the specimens before and after carburization is recorded. The analysis of the results illustrates that the hardness increases linearly with the increase in the reinforcement content within the matrix from $3 \mathrm{wt} . \%$ up to $9 \mathrm{wt}$.\%. It is also evident that the Volumetric Heat Capacities (VHC) of the chill material bears a strong effect not only on the quality of the castings produced but also on the hardness of the AMCs. Carburization leads to carbon deposition on the surface causing a change in the hardness of the specimens.
\end{abstract}

Keywords: Volumetric Heat Capacity; aluminium metal matrix composites; particulate reinforcement; hardness; directional solidification; stir casting.

\section{INTRODUCTION}

Composites, known for their tailorable properties, have found widespread applications. Over the past three decades, the research in the field of metal matrix composites has been primarily centred on aluminium as it is found to exhibit a unique combination of desirable properties such as low density, good corrosion resistance coupled with extremely good mechanical and thermal properties [1,2]. Aluminium is found to possess such properties that can be tailor made to suit specific requirements, especially the specific thermal properties such as coefficient of thermal expansion coupled with a good thermal conductivity [3]. This has enabled the large scale use of aluminium metal matrix composites in aerospace and avionics applications. The large scale adaptation of aluminium alloys is visible in the automobile, aero and space industries is in respect to 
reducing the fuel usage and thereby replacing successfully at a faster pace the use of monolithic metals such as steel and cast iron [4]. Over the past few years, various research work has proven the fact that the particulate reinforced aluminium metal matrix composites have clearly shown an excellent blend of good thermal and mechanical properties over continuously reinforced aluminium metal matrix composites [5, 6]. It is found that the particulate reinforcements produce almost perfect isotropic properties of the metal matrix composites which resulted in extensive use of the same in structural applications [7]. Glass, a ceramic material has attracted interest from many researchers to be used as a reinforcement in aluminium alloy metal matrix composite. This is due to its ease of availability, low cost and a very good ability is being used as a reinforcing phase along with a wide variety of aluminium alloy. It is also evident that glass particulate reinforced aluminium matrix composites exhibit an improved mechanical properties as compared to monolithic alloy [8]. It is clear from the aforesaid statements that aluminium alloy is the most sought after matrix material in the aerospace and automotive applications and is mostly reinforced with particulates for better mechanical and thermal properties. Though an extensive work has been undertaken to evaluate the mechanical and thermal properties of AMCs, very little literature is available that deals with the evaluation of the properties of such AMCs subjected to carburization, whereas such evaluations are extremely important from the fact that AMCs are widely employed to fabricate engine parts such as cylinder heads, pistons, connecting rod etc., which are constantly exposed to carbonaceous environments. The current paper discusses the effect of varied weight percent of borosilicate glass particulates on the hardness of aluminium alloy metal matrix composites fabricated with the help of end chills. The paper also discusses the effect of carburization on the cast composites through the evaluation of hardness after carburization. The work also evaluates the effect of different chill materials on the microstructure and hardness of the fabricated composites.

\section{METHODS AND MATERIALS}

\section{Matrix Material}

LM25 aluminium alloys are being extensively used to produce sound castings possessing superior mechanical properties. LM25 aluminium alloy due to its superior strength is now the most widely used casting material that exhibits fair resistance to corrosion. Its potential application areas have increased manifold owing to its availability under various conditions of heat treatment in both sand and chill castings [9]. LM25 is used in applications including food processing, chemical industries, marine structures, electrical appliances, and many other application areas. It has been markedly used for the production of blocks of cylinder heads, pistons and other engine and body parts for automobile industries. Thin leak tight castings can also be produced that are of sound quality and free from hot tearing. Hence, Aluminium alloy (LM25) is used as the matrix material in the present experimental investigation. The composition of the selected matrix alloy is illustrated in Table 1. LM25 alloy has been widely used in applications which require good mechanical properties and excellent castability so that the desired standard of soundness is achieved in the resulting castings. The alloy also possesses good corrosion resistance coupled with high strength $[10,11]$. 
Table 1. Elemental composition of LM25

\begin{tabular}{cccccccc}
\hline Elements & $\mathrm{Zn}$ & $\mathrm{Mg}$ & $\mathrm{Si}$ & $\mathrm{Cu}$ & $\mathrm{Mn}$ & $\mathrm{Fe}$ & $\mathrm{Al}$ \\
\hline $\begin{array}{c}\text { Composition } \\
\text { (wt.\%) }\end{array}$ & 0.10 & 0.37 & 7.00 & 0.20 & 0.10 & 0.20 & Balance \\
\hline
\end{tabular}

\section{Reinforcement}

A lot of effort has been done by the research fraternity to incorporate low cost, widely available industrial wastes as reinforcements in order to improve the economics of the resultant composite. The potential of Glass which is available in abundance as a byproduct resulting from the recycling of industrial wastes are now being explored as a possible reinforcement in metal matrices [12]. It has also been found that glass particulate reinforced aluminium matrix composites exhibit an improved mechanical properties as compared to monolithic alloy $[13,14]$. In the present investigation borosilicate glass will be selected as the reinforcement because of its properties such as high hardness (510 knoop hardness), toughness $(0.8 \mathrm{MPa}-\mathrm{m} 1 / 2)$, and high melting point $\left(560{ }^{\circ} \mathrm{C}\right)$, low cost and easy availability. Chemical configuration of the borosilicate glass is given in Table 2 .

Table 2. Chemical composition of borosilicate glass

\begin{tabular}{cc}
\hline Elements & $\begin{array}{c}\text { Weight \% } \\
\text { (approximate) }\end{array}$ \\
\hline Silicon di oxide & 80.6 \\
Boron Oxide & 13.0 \\
Sodium Oxide & 4.0 \\
Aluminium Oxide & 2.3 \\
Miscellaneous & 0.1 \\
\hline
\end{tabular}

\section{End Chill Materials}

Chills are specific objects that are judiciously placed in the mould cavity so as to promote directional solidification. The chills are imperative to produce sound castings and that the soundness of the casting depend upon the size and placement of the selected chills within the mould [15]. External chills of different volumetric heat capacities are employed in the present work to improve the microstructure and thermos-physical properties of the composites. Table 3 depicts the thermo-physical properties of materials of various end chills selected for the present work. Figure 1 shows the four chills made out of four different materials that were used for the preparation of specimens.

Table 3. Thermo-physical properties of end chill materials

\begin{tabular}{cccc}
\hline Elements & $\begin{array}{c}\text { Thermal } \\
\text { conductivity } \\
(\mathrm{W} / \mathrm{m} \mathrm{K})\end{array}$ & $\begin{array}{c}\text { Volumetric Heat } \\
\text { Capacity for 25 } \\
\text { mm chill }(\mathrm{J} / \mathrm{K})\end{array}$ & $\begin{array}{c}\text { Specific } \\
\text { heat } \\
\text { Capacity } \\
(\mathrm{J} / \mathrm{kg} \mathrm{K})\end{array}$ \\
\hline Copper & 1.022 & 597.0 & 0.448 \\
Mild Steel & 0.109 & 491.5 & 0.421 \\
Cast Iron & 0.160 & 453.9 & 0.401 \\
Silicon Carbide & 0.039 & 384.3 & 1.095 \\
\hline
\end{tabular}




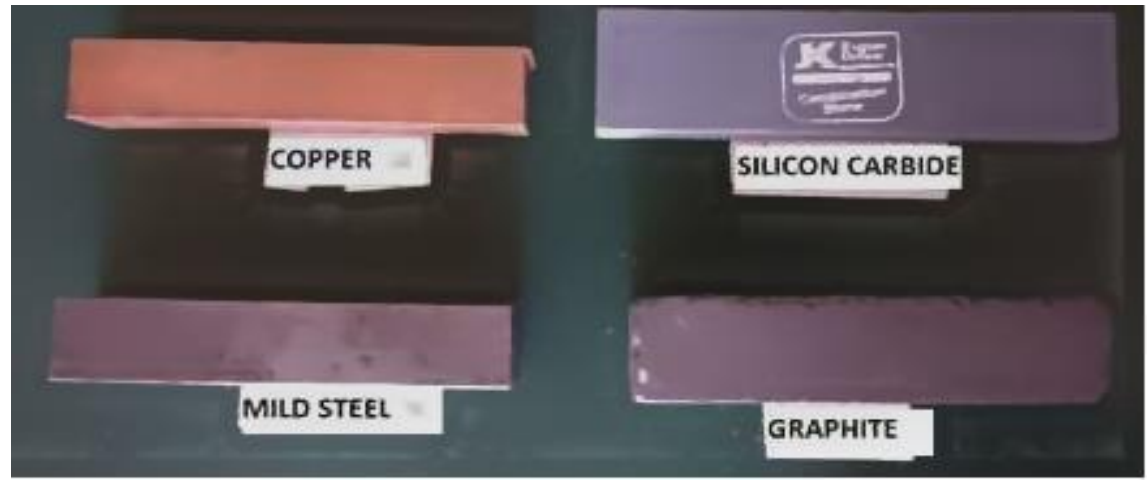

Figure 1. End chills employed in the current work.

\section{Chill Casting of the Composites}

The objective of the present research is to produce quality castings of aluminium alloyborosilicate glass particulate composites with the aid of sand moulds incorporating copper, mild steel, graphite and silicon carbide end chills through the dispersion of borosilicate glass particles in the melt of aluminium alloy present at a temperature that is higher than the temperature at which the alloy is in liquid state. Aluminium alloy LM25 ingots are procured through suitable vendors and is melted in an induction furnace at around $750{ }^{\circ} \mathrm{C}$; preheating of the borosilicate glass particulates was carried out until the reinforcements attained a temperature of approximately $750{ }^{\circ} \mathrm{C}$ to avoid the thermal mismatch between the matrix and reinforcement phase.

\section{Stir Casting of the Composites}

Stir casting process is used to prepare the required composites that are reinforced with varied weight percentages of borosilicate glass particulates. Stir casting is considered to be the novel, economical and most widely used method of fabricating the composites with less porosity $[16,17]$. The setup of the stir casting arrangement is shown in Figure 2.

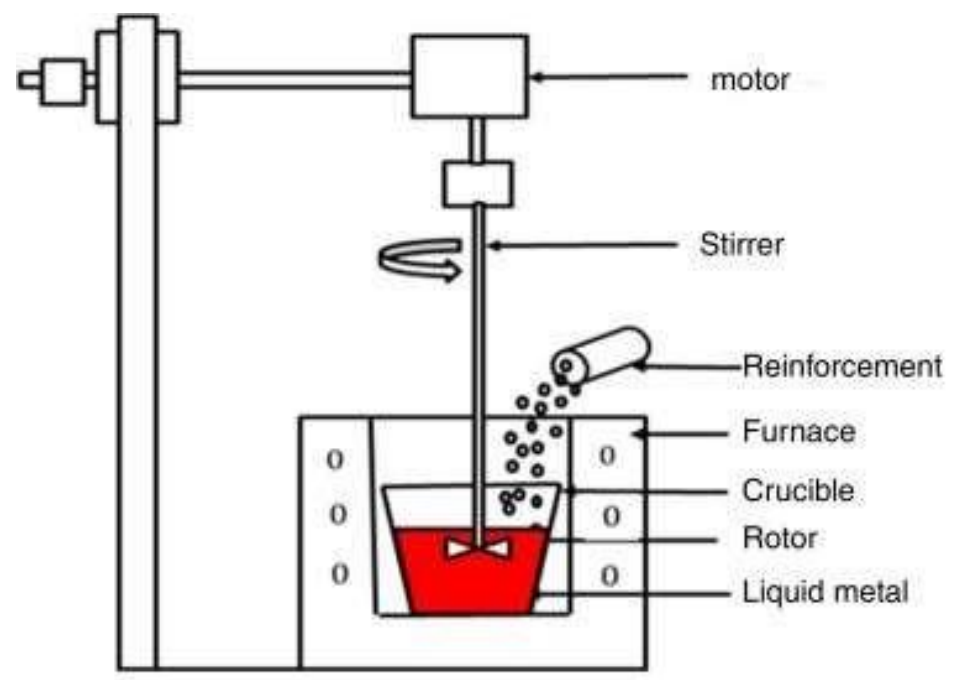

Figure 2. Stir casting setup.

The dispersoid weight content within the matrix ranges from 3 to 12 wherein at every iteration 3 weight percent of dispersoid was added to the existing dispersoid content. Borosilicate glass particulates of $100 \mu \mathrm{m}$ size are poured into the molten alloy with the 
aid of a proper feeding attachments. Meanwhile, the molten metal matrix composites were well agitated by means of an electromechanical stirrer rotated at around 800 revolutions per minute for about 10 minutes. The molten melt is then poured into a thoroughly airdried sand mould consisting of judiciously placed end chills as illustrated in Figure 3. Figure 4 illustrates the final cast specimens obtained using different end chills.

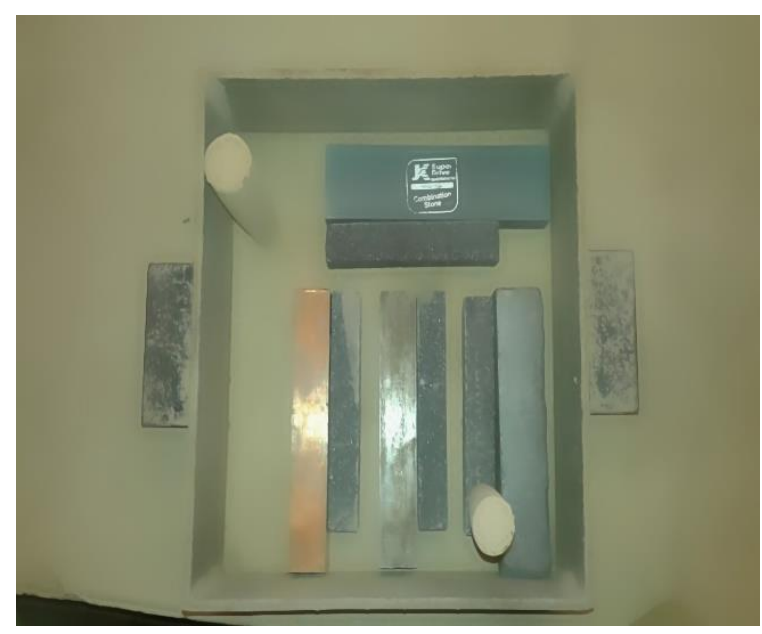

(a)

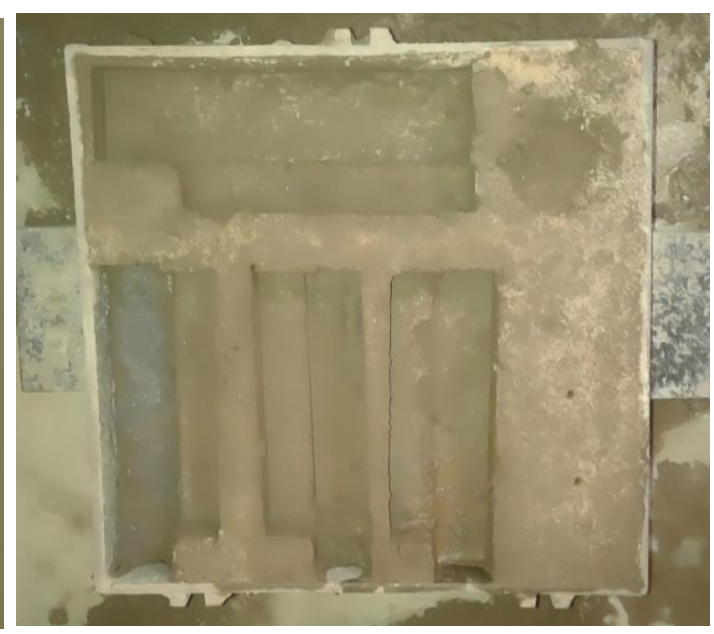

(b)

Figure 3. Mould preparation with chills (a) placement of chills; (b) sand mould with arrangements for placement of chills.

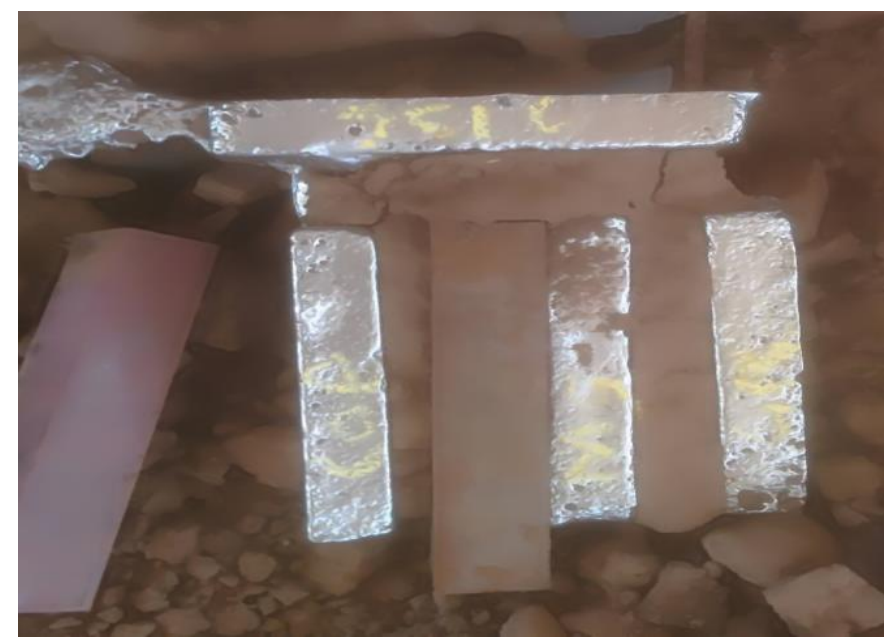

Figure 4. Cast MMCs.

\section{Preparation of test specimens}

Specimens for micro-hardness test were prepared according to American Foundry men Society (AFS) standards. The specimens were taken from various locations in the casting, namely at the chill end and $10 \mathrm{~mm}$ from the chill end. The specimens prepared were first used for microstructural examination, followed by hardness test and were later used for carburization test.

\section{Microstructural studies}


The casted Metal Matrix Composite was machined to obtain the specimens at the chill end. The specimens thus obtained were polished first on a 1000 grit emery paper and then were further buffed on a polishing machine by applying a diamond paste. The polished specimens were further etched with Keller's reagent and were set in a wax mould as shown in Figure 5. The specimens, then, were studied under an optical metallurgical microscope to analyse the distribution of reinforcement within the matrix material. Pictomicrographs of the specimen under varied magnifications were captured for the purpose of microstructural studies.

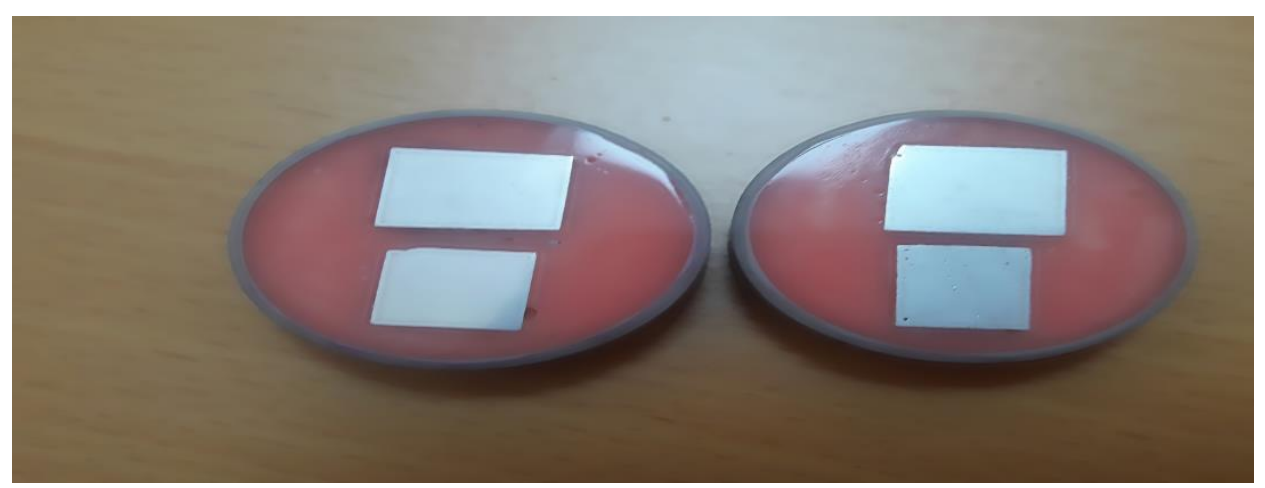

Figure 5. Polished specimens set in wax mould for microstructural examination.

\section{Microhardness test}

Vicker's micro hardness test was performed on all the samples prepared from the composites fabricated using different chills and by varying the weight percentage of the dispersoid. A load of $100 \mathrm{~g}$ was applied over a dwell time of 15 seconds. The hardness was recorded using the diagonal length of the indentation produced. The tests were carried out at three different locations in each specimen to avoid the possibility of indenter resting on any particular reinforced borosilicate glass particle.

\section{Carburization Test}

Pack carburization was carried out with the help of a muffle furnace. The specimens were placed inside a graphite crucible filled with charcoal powder. The crucible was then sealed with the help of clay. The sealed crucible was then charged into a muffle furnace maintained at $500^{\circ} \mathrm{C}$ and held at that temperature for 50 hours. For aluminium and its alloys the carburization effect is evident at $350^{\circ} \mathrm{C}$ [18]. Hence the carburization temperature of about $500^{\circ} \mathrm{C}$ is chosen in the present work. Figure 6 depicts the packing of specimens for carburization.
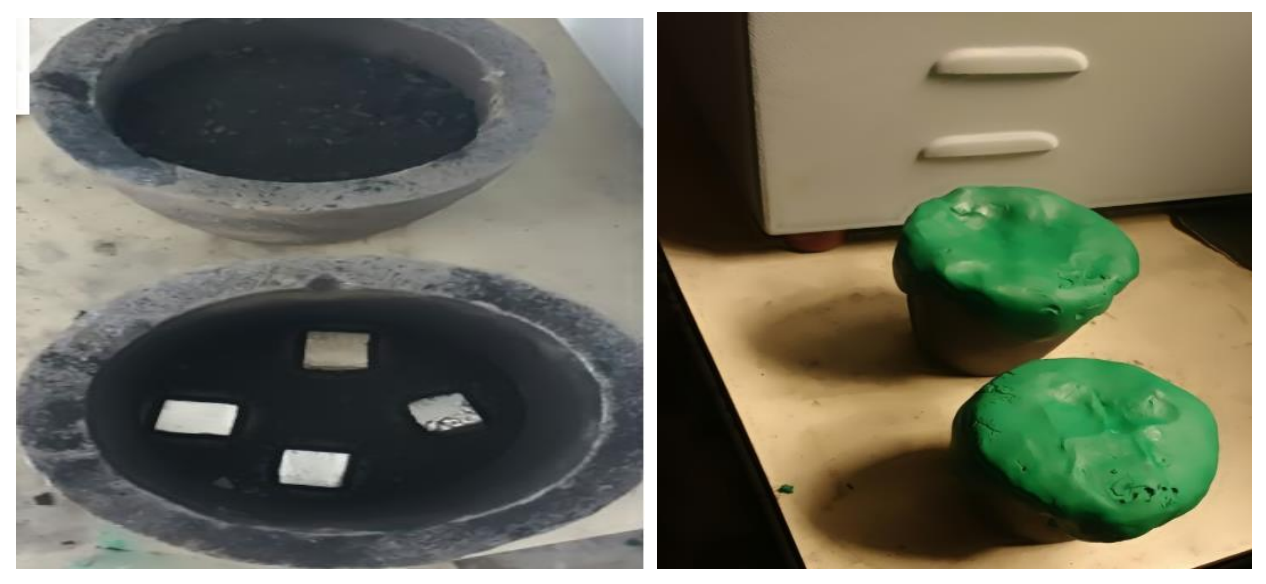
(a)

Figure 6. Specimens packed in charcoal before carburization (a) crucible before sealing; (b) crucible after sealing.

\section{RESULTS}

\section{Microstructural Examination}

The aim of the current research work is to produce sound castings of aluminium alloyborosilicate glass particulate composites with the help of copper, mild-steel, silicon carbide and graphite end chills placed strategically in the mould cavity. The microstructure of the fabricated MMCs reinforced with $9 \mathrm{wt} \%$ reinforcement using two metallic (Copper and Mild Steel) and two non-metallic (Graphite and Silicon Carbide) chills are shown in Figure 7(a) to (d) respectively. The length scale used for obtaining the microstructure is $25 \mu \mathrm{m}$.

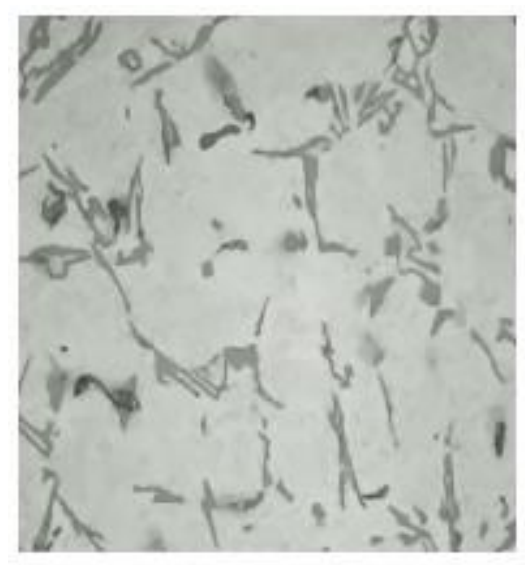

(a)

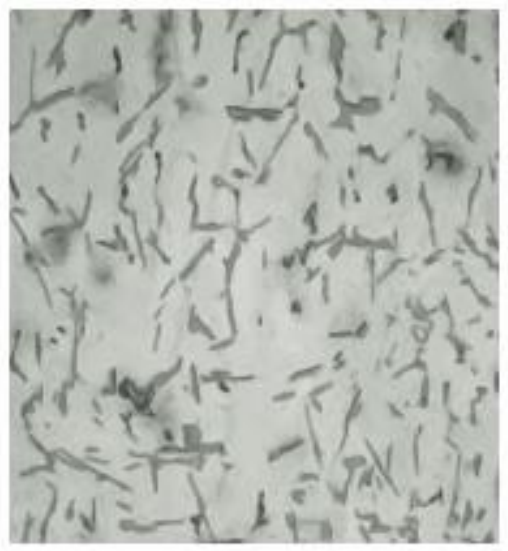

(c)

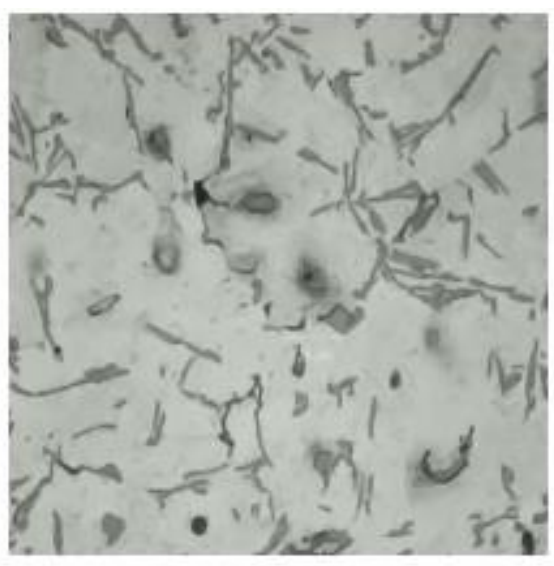

(b)

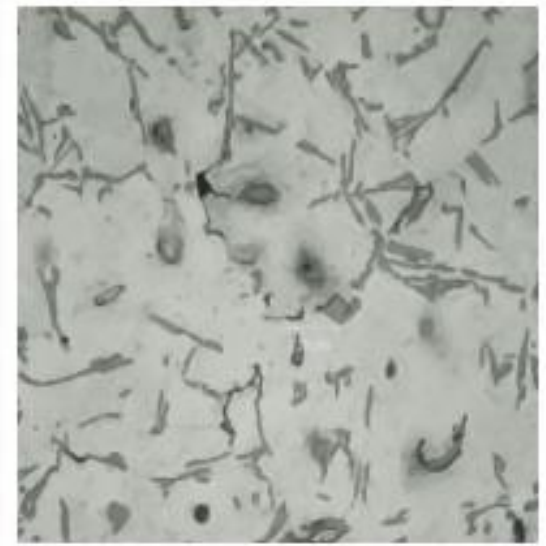

(d)

Figure 7. Optical pictographs of the fabricated MMC (9wt.\% reinforcement) with different end chills (a) copper chill (b) mild steel chill (c) graphite chill (d) silicon carbide chill.

\section{Microhardness}

The results of microhardness test (HV) conducted on the samples prepared from the chilled LM25-borosilicate glass powder metal matrix composites are shown in Figure 8. 
The figure illustrates the effect of varying the weight percentage of reinforcement and also the effect of different chill materials on the hardness of the prepared composite material specimens. The figure clearly show that the hardness of the composite increases with increase in the reinforcement content. The increase in the hardness of all the specimens is seen up to $9 \mathrm{wt}$. \% borosilicate glass and any further addition of the reinforcement tends to reduce the hardness of the composites. Results of microhardness measurements also revealed that copper chill has a good effect on the hardness of the composites as compared with other chills. Also, it is evident that the specimens prepared with the incorporation of metallic chills possess higher hardness value as compared to the specimens fabricated with non-metallic end chills. The hardness value is also dependent on the distance from the end chill as shown in Figure 9.

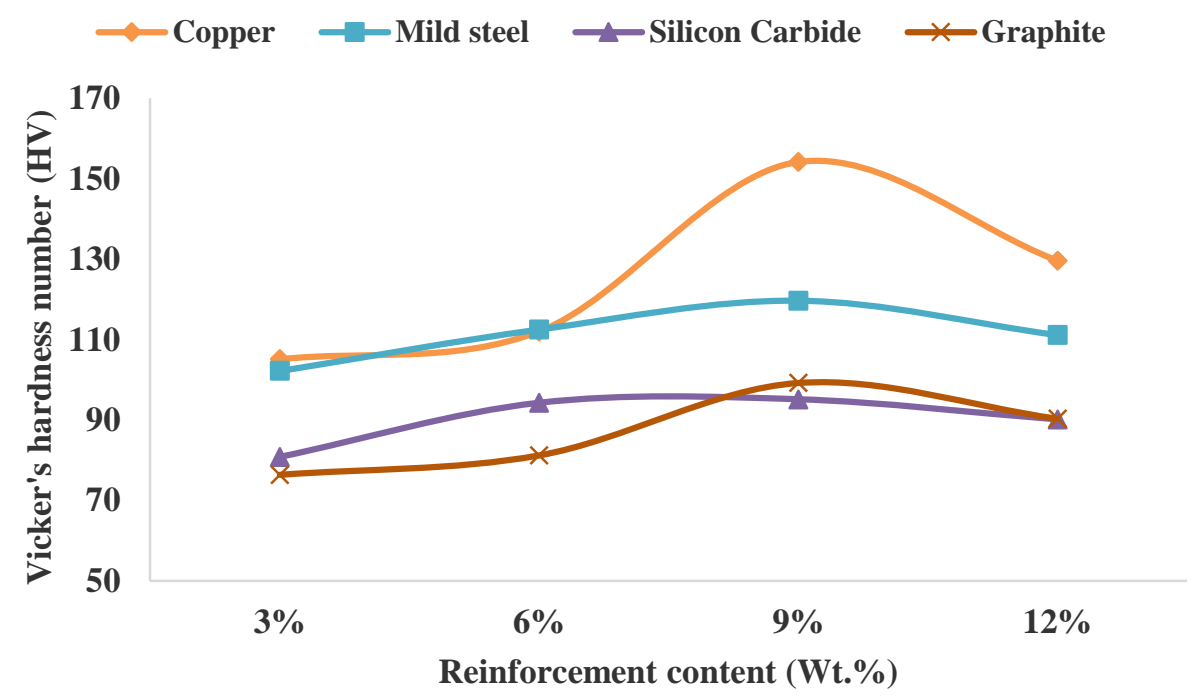

Figure 8 . Hardness v/s weight percent borosilicate glass reinforcement.

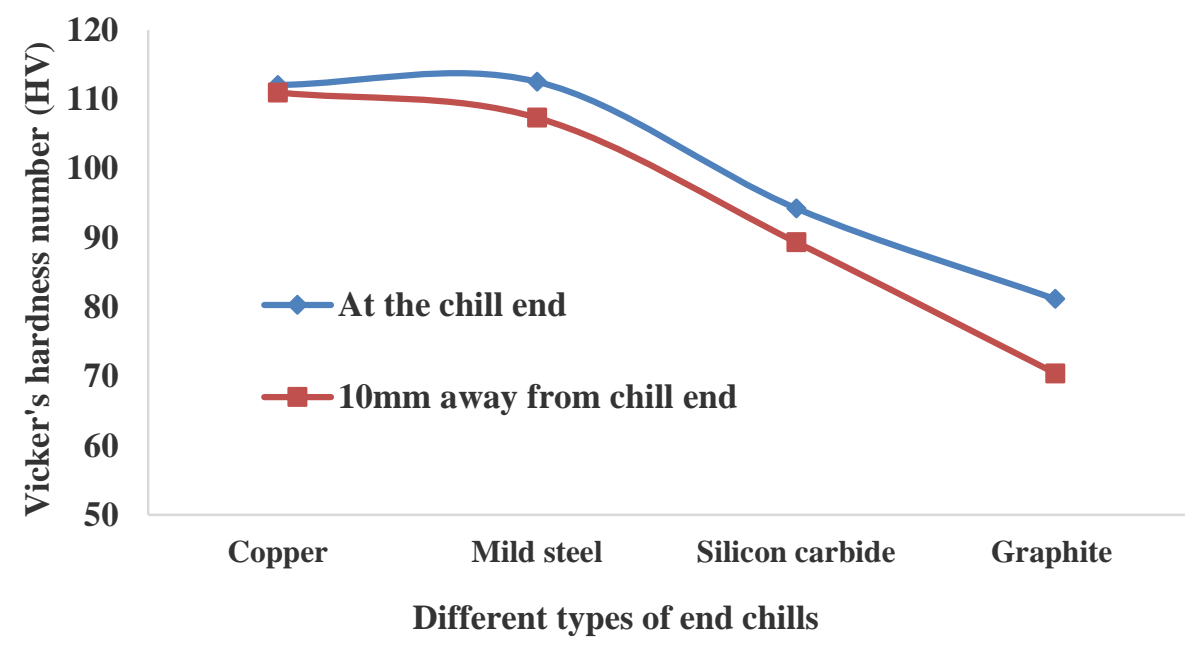

Figure 9. Hardness of MMC (6 weight percent borosilicate glass powder) v/s distance from chill end.

\section{Carburization}

Aluminium matrix composites are the most sought after material in the field of automotive and aerospace. Under such severe operating conditions the material is 
constantly exposed to a carbonaceous environment and thus an effort has been made to study the impact of such carbon deposition on the hardness and microstructure of the material. Here, the effect of carburization primarily on the hardness of the material is studied and not on the other mechanical properties due to the reason that carburization leads to embrittlement of the material to a major extent and thus hampering the material's hardness value. The SEM images in Figure 10 indicates the carbon deposition after carburization for 50 hours. Figure 11 illustrates the effect of carburization on the hardness of the material.
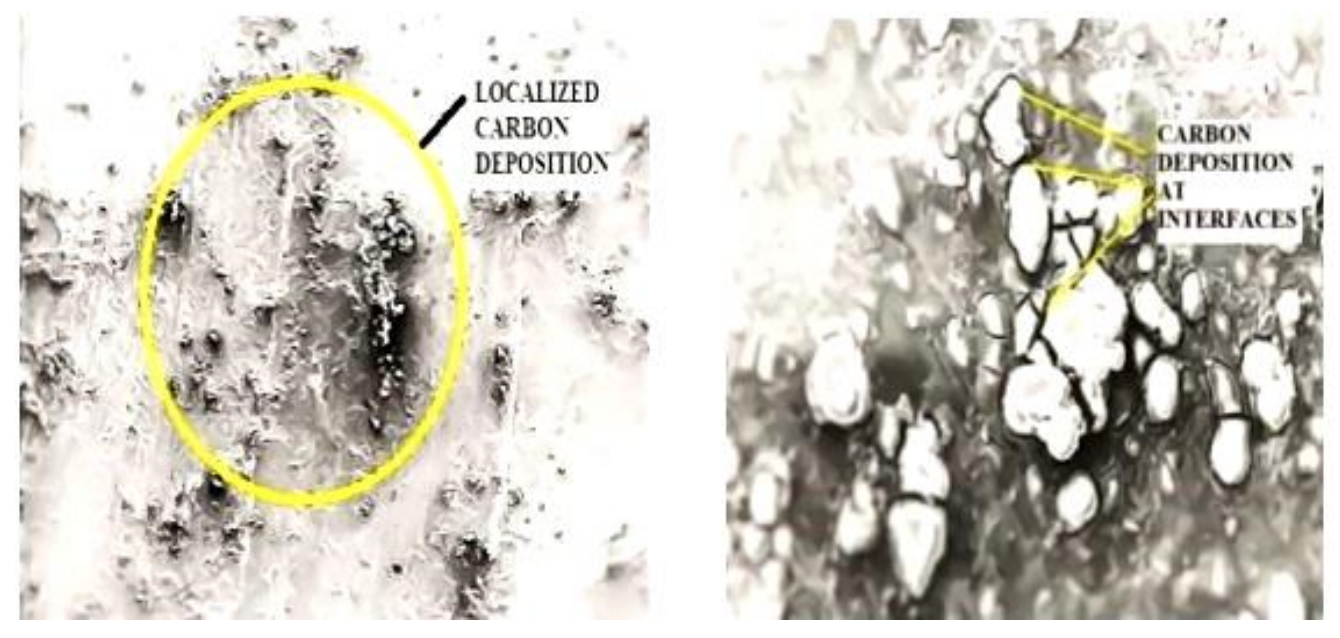

Figure 10. Carbon deposition after carburization (scale: $10 \mu \mathrm{m}$ ).

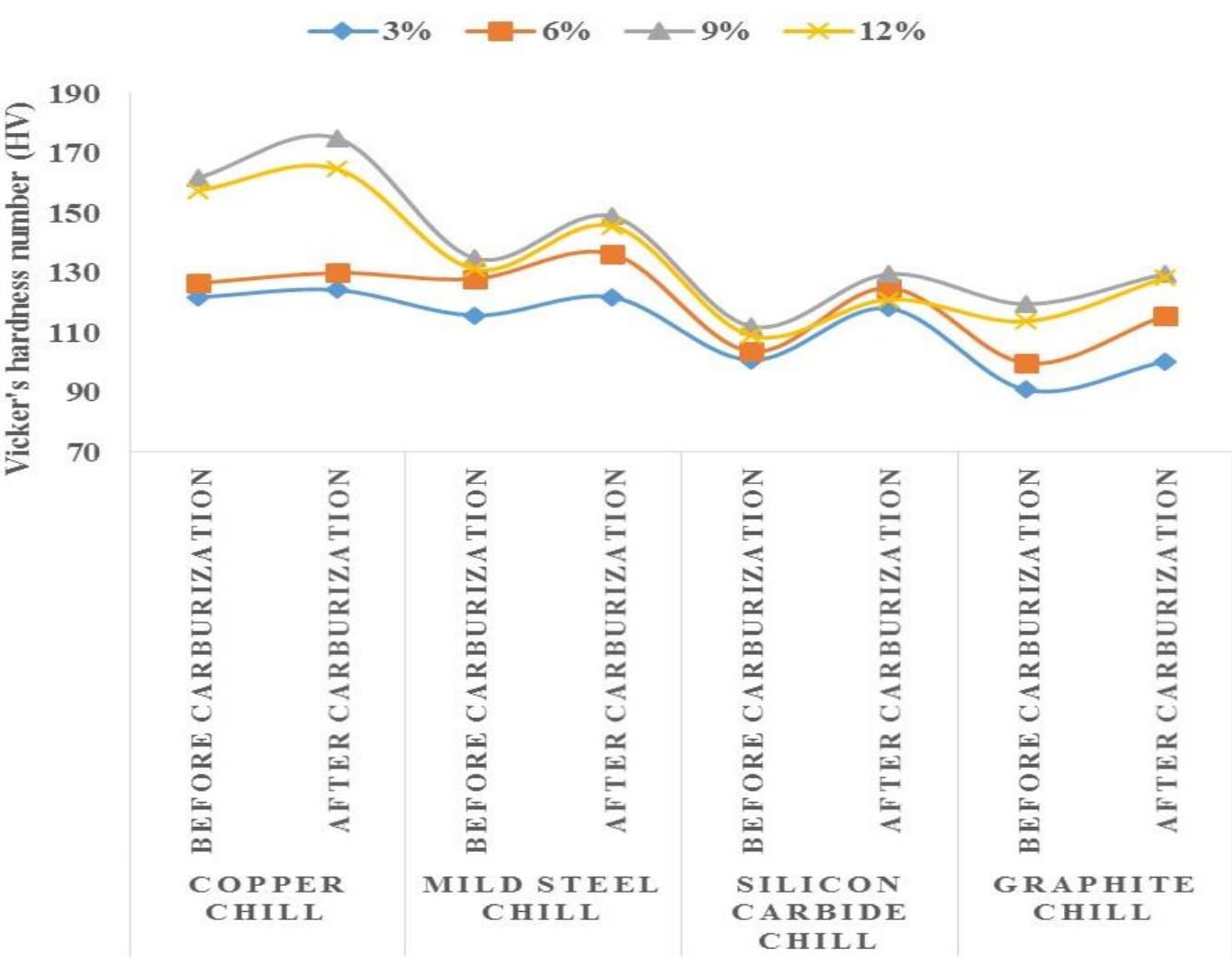

Figure 11. Effect of carburization on the hardness of the material. 


\section{DISCUSSIONS}

\section{Microstructural Examination}

Microstructure has a major say in the quality of the mechanical properties gained by the fabricated composites. Though there are numerous processing parameters that play a role in the evolution of microstructure, it is the rate at which the castings are cooled that determine in how refined the microstructure of a particular material is. Thus, the final structure of a material largely depends upon the cooling conditions achieved during solidification [19]. Analysis of Figures 7(a) to 7(d) results in the conclusion that the microstructure depicted in Figure 7(a) is more refined than the other microstructures depicted in Figure 7(b), 7(c) and 7(d) respectively. Figure 7(a) illustrates the microstructure of $9 \mathrm{wt} \%$ borosilicate glass particulate reinforced AMC fabricated with the help of copper end chill. The volumetric heat capacity (VHC) of the copper chill is higher than the VHCs of other chills used in the current work. The higher VHC of the copper chill helps in directional solidification coupled with an accelerated cooling rate. The accelerated solidification yields a refined grain structure and ensures improved mechanical properties [20, 21]. Hence, the microstructure of the AMC cast with copper end chill is more refined in comparison with the microstructure of AMCs cast with mild steel, graphite and silicon carbide end chills respectively. Also, the optical pictographs associated with metallic end chills (Figure 7(a) and 7(b)) are more refined in comparison with those associated with non-metallic end chills (Figure 7(c) and 7(d)). This is due to the fact that VHC of metallic end chills is higher than that for non-metallic end chills.

\section{Microhardness}

The increase in the hardness of the cast AMCs can be attributed primarily to presence of harder borosilicate glass ceramic particulates in the matrix. Chilling also has a role to play in the improved hardness of the composites as chilling results in a reduced grain size which in turn resists the localized deformation during indentation. Figure 8 shows the graph of hardness of MMCs with different wt. \% of reinforcement content which confirms the positive relationship between hardness and the reinforcement content up to $9 \mathrm{wt} . \%$ reinforcement . For 12 wt.\% reinforcement addition, the hardness value reduces in comparison to $9 \mathrm{wt} . \%$. This may be due to the fact that higher concentration of dispersoid within the matrix leads to segregation, clustering and settling of the reinforcing particles within the matrix. Hence, at $12 \mathrm{wt} . \%$ addition of borosilicate glass particles, the matrix is devoid of even and uniform distribution of the hard reinforcement and hence we see a drop in the hardness value of the composite.

Chilling also has a role to play in the improved hardness of the composites as chilling results in a reduced grain size which in turn resists the localized deformation during indentation. Copper with a high Volumetric Heat Capacity results in faster heat extraction from the MMC during casting resulting in a refined grain structure of the cast AMCs and this fact is evident from the results obtained which shows that the hardness value of the MMCs fabricated with copper chill is higher as compared with the hardness value of MMCs fabricated with other chills.

When there is a uniform and even distribution of the dispersoid within the matrix, the hardness value of the cast composite ingot should be same throughout its length and breadth. However, for particle reinforced composites, the hardness value tends to differ through its length and breadth due to many parameters that include the gravity effect, uneven cooling rate etc. In order to evaluate this, specimens are drawn from the chill end and $10 \mathrm{~mm}$ away from the chill end. The results clearly indicate that the hardness 
decreases as the distance from the chill increases. This reinforces the above drawn conclusion that higher cooling rates that are evident near the chill end results in finer grain structure and as the distance from the chill end increases the hardness value tends to drop due to reduced cooling rates leading to uneven distribution of the dispersoid within the matrix. These results reinstates the fact that increasing the rate of chilling tends to increase the hardness of the material.

\section{Carburization}

Carburization has a direct impact on the hardness of the material as indicated in Figure 11. It is a well investigated fact that aluminium and its alloys tend to form a protective carbide layer of aluminium Carbide $\left(\mathrm{Al}_{4} \mathrm{C}_{3}\right)$ when exposed to carbonaceous environments. This reaction is as shown below:

$$
4 \mathrm{Al}+3 \mathrm{C}=\mathrm{Al}_{4} \mathrm{C}_{3}
$$

There is localized deposition of the carbon between the interfaces through the porous carbide layer formed over aluminium alloy matrix composites. The deposition is visible through the SEM images illustrated in Figure 10. It is also evident from the results that the hardness of the carburized specimens also increases due to the deposition of amorphous carbon and also due to the formation of extremely hard carbide layers over the composite surfaces.

\section{CONCLUSION}

The findings of the work indicate that though AMCs attract extensive attention in the field of automotive and aerospace, one cannot refute the fact that these materials are not alien to the severe operating conditions and hence, a judicious caution needs to be employed in arriving at a proper reinforcement content within the matrix and a proper control over various processing parameters has to be ensured. Employment of end chills with higher VHC aids in directional solidification of the melt in the mould cavity and ensures a refined grain structure to develop within the castings. The hardness of the composite fabricated has a linear incremental relationship with the weight percent addition of borosilicate glass powder into the LM25 alloy matrix. But, addition of more than 9 wt.\% of borosilicate glass powder dispersoid into LM25 metal matrix results in clustering and settling of the reinforcement in the matrix leading to uneven distribution of the reinforcement. This in turn reduces the hardness of the fabricated composite. The carburization of the fabricated composite leads to deposition of carbon between the interface regions and forms a brittle, hard carbide layer over the surface of the composite. This increases the hardness of the carburized specimens.

\section{ACKNOWLEDGMENT}

We acknowledge our sincere thanks to Dr. Joel Hemanth, who has been a constant source of inspiration and guidance in persuasion of this work. We also thank H.M.S. Institute of Technology, Tumkur, India, for providing the casting facilities required for this work. 


\section{REFERENCES}

[1] Chatzimichali AP, Potter KD. From composite material technologies to composite products: a cross-sectorial reflection on technology transitions and production capability. Translational Materials Research. 2015; 2(2):026001.

[2] Natarajan N, Krishnaraj V, Davim JP. Metal matrix composites: synthesis, wear characteristics, machinability study of MMC brake drum. Springer; 2014.

[3] Maleque MA, Radhi M, Rahman MM. Wear study of Mg-SiCp reinforcement aluminium metal matrix composite. Journal of Mechanical Engineering and Sciences. 2016;10:1758-1764.

[4] Kalhapure MG, Dighe PM. Impact of silicon content on mechanical properties of aluminum alloys. Int. J. Sci. Res. 2015;4:38-40.

[5] Subramanian J, Seetharaman S, Gupta M. Processing and properties of aluminum and magnesium based composites containing amorphous reinforcement: A review. Metals. 2015;5(2):743-762.

[6] Khan MM, Dixit G. Erosive wear response of SiCp reinforced aluminium based metal matrix composite: Effects of test environments. Journal of Mechanical Engineering and Sciences. 2017;14:2401-2414.

[7] Huang LJ, Geng L, Peng HX. Microstructurally inhomogeneous composites: is a homogeneous reinforcement distribution optimal?. Progress in Materials Science. 2015;71:93-168.

[8] Thandalam SK, Ramanathan S, Sundarrajan S. Synthesis, microstructural and mechanical properties of ex situ zircon particles $\left(\mathrm{ZrSiO}_{4}\right)$ reinforced metal matrix composites (MMCs): a review. Journal of Materials Research and Technology. 2015;4(3):333-347.

[9] Bharathi V, Ramachandra M, Srinivas S. Comparison of dry and wet sliding wear behavior of squeeze cast aluminum alloy. Indian Journal of Advances in Chemical Science S1. 2016;101:106.

[10] Hiremath A, Hemanth J. Fabrication and impact of chills on the strength of chilled aluminum alloy-borosilicate glass particulate composite. International Journal of Applied Engineering Research. 2015;10(20):41685-41688.

[11] Hussain F, Abdullah S, Nuawi MZ. Effect of temperature on fatigue life behaviour of aluminium alloy AA6061 using analytical approach. Journal of Mechanical Engineering and Sciences. 2016;10(3):2324-2335.

[12] Kumar AR, Malayalamurthi R. Reuse of industrial waste soda white lime glass powder and sic as reinforcements to improve properties of composite material. Asian Journal of Research in Social Sciences and Humanities. 2016;6(9):15371553.

[13] Pramod SL, Bakshi SR, Murty BS. Aluminum-based cast in situ composites: a review. Journal of Materials Engineering and Performance. 2015;24(6):21852207.

[14] Mousavian RT, Khosroshahi RA, Yazdani S, Brabazon D, Boostani AF. Fabrication of aluminum matrix composites reinforced with nano-to micrometersized SiC particles. Materials \& Design. 2016;89:58-70.

[15] Copur M, Turan A, Eruslu MN. Effects of chills on the solidification pattern of an axial steel cast impeller. Metalurgija. 2015;54(3):515-518.

[16] Junus S, Zulfia A, Mariani L. Effect of magnesium on hardness and microstructure of metal matrix composite $\mathrm{Al} 6061 /\left(\mathrm{Al}_{2} \mathrm{O}_{3}\right)$ p produced by stir casting route. In Advanced Materials Research. 2015;1112:381-384. 
[17] Kumar B, Menghani JV. Aluminium-based metal matrix composites by stir casting: a literature review. International Journal of Materials Engineering Innovation. 2016;7(1):1-4.

[18] Pirizadhejrandoost S, Bakhshzad Mahmoudi M, Ahmadi E, Moradshahi M. The corrosion behavior of carburized aluminum using DC plasma. Journal of Metallurgy. 2012;258021.

[19] Hemanth J. Action of chills on soundness and ultimate tensile strength (UTS) of aluminum-quartz particulate composite. Journal of alloys and compounds. 2000;296(1-2):193-200.

[20] Bandekar N. Study of Dispersoid content and chill effect for improved mechanical properties of aluminum-garnet-carbon hybrid metal matrix composites. International Journal of Engineering Technology, Management and Applied Sciences. 2015;3:616-623.

[21] Hiremath A, Hemanth J. Experimental evaluation of the chill casting method for the fabrication of LM-25 aluminum alloy-borosilicate glass (p) composites. InKey Engineering Materials. 2017;748:69-73. 